\title{
Sugarcane Farmers Perception, Comprehension Regarding Climate Change and its Mitigation Through Adoption of Cultural Practices
}

\author{
Hafiz Ali Raza ${ }^{*}$, Rana Muhammad Amir ${ }^{1}$, Farzana Zaheer Syed ${ }^{2}$, Muhammad Shoaib Ajnum ${ }^{3}$, Imran Kareem¹, \\ Muhammad Abdullah Saad ${ }^{4}$, Muhammad Hussnain ${ }^{4}$, Muhammad Sohail Qadir ${ }^{5}$ \\ 1 Institute of Agri. Extension and Rural Development, University of Agriculture Faisalabad, Pakistan. \\ ${ }^{2}$ Department of political science, Government Collage Women University Sialkot, Punjab, Pakistan. \\ ${ }^{3}$ Department of Plant Pathology, University of Agriculture Faisalabad, Pakistan. \\ ${ }^{4}$ Department of Agronomy, University of Agriculture Faisalabad, Pakistan. \\ ${ }^{5}$ Department of Entomology, of Agriculture Faisalabad, Pakistan.
}

\section{AR T I C L E I N F O}

\section{Article History}

Received: January 16, 2020

Revised: March 11, 2020

Accepted: March 13, 2020

\section{Keywords}

Climate Change

Growers

Sugarcane Production

Adoption Practices

\section{A B S T R A C T}

Sugarcane is an important cash crop in Pakistan. Recently, the average per hectare production of sugarcane is low due to climatic variation. Therefore, sugarcane farmers are threatened by this emerging issue that has drastically affected their livelihoods, food security, and sustainability. This study was designed to analyze the perception, comprehension, and adoption of cultural practices in the mitigation of the impact of climate change. For this purpose, district Rahim Yar Khan was selected purposively from the Province of Punjab as the universe of the study; as one of the highly cultivated areas among all districts of Punjab. From selected districts, two tehsils were randomly selected, namely Sadiqabad and Khanpur. From each selected tehsil, 5 villages were selected using randomized sampling technique. In each selected village, 18 sugarcane farmers were selected randomly thus, making a total of 180 respondents. The data were collected through quantitative methods. A pre-tested and well-structured interview schedule was developed for the collection of information from sugarcane farmers. Data were analyzed using both descriptive and inferential statistics through the Statistical Package for Social Sciences. Results indicated that there was a significant difference between the two groups, adopter and non-adopters of mitigation strategies towards climate change. The results revealed that the majority ( $98.3 \%$ and $75 \%$ ) of the growers reported that an increase in temperature and deforestation for the last five years respectively. Moreover, residues burring and deforestation were major causes of climate change followed by an excess of $\mathrm{CO} 2$ from agriculture activities and farm operations. The study recommended that the adoption of cultural practices in mitigation of the impact of climate change should be promoted through information sources.

Corresponding Author: Hafiz Ali Raza

Email: razaa0617@gmail.com

(c) The Author(s) 2020.

\section{INTRODUCTION}

Sugarcane production in Punjab is 49.6 Million tons and a total cultivated area of 0.777 million hectares (Chatta et al., 2018). Sugarcane is the second major provider of sweetener after honey in Pakistan (Qureshi and Afghan, 2005) and it provides the raw material for the second agro-based industry after textiles. However, in recent times sugarcane is recognized for its role in sustainable 
sugarcane production (Prasara-A and Gheewala, 2016). Different products are obtained from sugarcane like sugar, jaggery and ethanol. In Pakistan, ethanol is produced at a small scale in sugar industries and does not play a significant role in Pakistan's economy whereas $80 \%$ sugar is produced from it. However, at national level the average per hectare production of sugarcane is low due climate change (Nadeem et al., 2020; Zhao and Yang 2015). Climate change is one of the emerging issues in the world. Livelihood and agricultural productivity are adversely affected by the climate change. It is predictable to have a negative impact on sugarcane production. Sugarcane is sensitive to climatic parameters such as rainfall, temperature, sunlight, and soil (Trenberth, 2011). It is believed that global temperatures will rise from $3-5^{\circ} \mathrm{C}$ by the end of the 21stcentury (Chohan, 2019). Diverse climatic conditions can lead to changes in sea level, rainfall, floods, droughts, abiotic pressures, and especially rising temperature. The increase in temperature could be favorable for some crops like C3 plants and sugarcane in some parts of the world (Trenberth, 2012). However, in Pakistan, the production of sugarcane is adversely affected and is cause of infestation of various diseases and pests. Amid many reasons of rising temperature, one of the main causes is change in human activities and more deforestation, burning fossil fuel and industrialization in the ecosystem (Chohan, 2019; Shakoor et al.2019). Variation in temperature, rainfall, floods, salinity, dryness, and frost have proven to be the main causes of the deterioration in sugarcane production in Pakistan (Chohan, 2019). Therefore, accurate perception regarding climatic variation and proper adoption of mitigation strategies can reduce the sugarcane economical losses (Abid et al., 2019). The present situation is creating a gap between farmers' awareness regarding agronomic measures including resistant varieties, sowing time and planting methods, land and soil preparation, weed, pest and disease management, water and nutrients management. The main objective of the research was to identify the climate change perception, apprehension, and its strategies through adoption of cultural practices as well as perceived attitude of the sugarcane farmers towards climate change in District Rahim Yar Khan, Punjab.

\section{METHODS AND MATERIAL}

The study was conducted through primary data from sugarcane growers of the province of Punjab in Pakistan. At the first stage, district Rahim yar khan was selected purposively from the Province of Punjab as the universe of the study because of the largest sugarcane cultivation area in this district as compared to any other district of Punjab. Next, two tehsils (Sadiqabad and Khanpur) were selected on random basis. At the third stage, 5 villages were selected randomly from each selected tehsil. At the fourth stage, 18 sugarcane farmers were selected randomly from each selected village and thus, making a total of total aggregate of 180 sugarcane growers. The data were collected through quantitative method. The quantitative data were collected through the well-structured questionnaire supplemented with the interview schedule. The validity of the interview schedule was tested by using Statistical Package for Social Sciences (SPSS). Cronbach Alpha for questions in the different objectives varied from 0.82 to 0.95 . Further to check reliability the data collection tool was also presented to the experts of the Institute of Agri. Extension, Education and Rural Development, UAF, Punjab and necessary amendments were made. The interview schedule was further pre-tested on 20 respondents (that were other than the purposively selected 180 sugarcane farmers). In the last wellstructured interview, the schedule was developed for data collection. The data were analyzed using both descriptive and inferential statistics through the Statistical Package for Social Sciences (SPSS). 




Figure 1. Flow chart showing sample selection procedure for the purposed study.

\section{RESULTS AND DISCUSSION}

The awareness level of the respondents regarding the cultural practice is presented in figure 2 . The majority of the sugarcane growers (71 \% - 90.6\%) had awareness about seed treatment before sowing, proper weed control management practices, mix cropping and properly weed control diseases management, respectively. It shows that majority of the respondents had basic awareness about the cultural practices in the study area against climate change.

The rates of the cultural practices adopted by sugarcane growers against climate change in the study area are presented in figure 2 . Almost $46.7 \%$ of the respondents were properly ploughing practices, followed by $45.6 \%$ and $45 \%$ of the sugarcane growers adopted properly control diseases management and sowing recommended varieties to mitigate the impact of climate change. The results are line with Khan et al. (2020) who indicated that recommended cultural practices are important to mitigate the impact of climate change at farm households. The overall adoption rates of the cultural practices were $50 \%$ or less. This indicate that the adoption rate of these practices was low as compared to awareness level. Slower adoption rate might be due to lack of interest of the farmers towards the climate change impact and lack of awareness level by the extension workers to motivate the growers regarding the importance of the adoption of practices to mitigate the impact of climate change. Adoption strategies with special reference to cultural practices under climate change might be important to enhance sugarcane tolerance against the climate change (Deressa et al., 2005). 


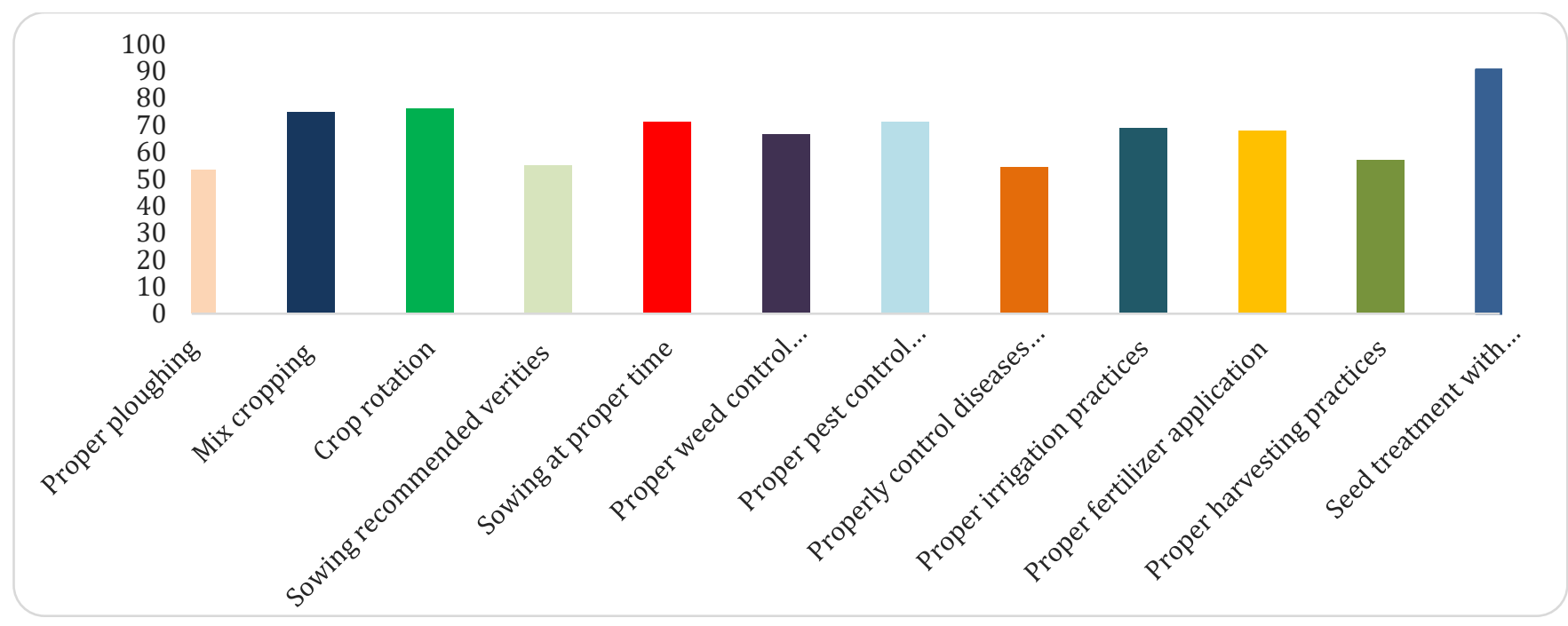

Figure 2. Perceived awareness level of cultural practices towards climate change in the study area.

Seed treatment with fungicides before sowing Proper harvesting practices Proper fertilizer application Proper irrigation practices Properly control diseases management Proper pest control management Proper weed control management Sowing at proper time Sowing recommended verities Crop rotation Mix cropping Proper ploughing



0 20 40 60 80 100

Figure 3. Perceived adoption of cultural practices towards climate change in the study area.

Respondent's responses regarding reasons of climate change are shown in Table 1. Perceived comprehension associated with climate change were measured by using three different scale ranging from 1 (large extent), 2 (some extent) and 3 (medium extent). Results indicated that residue burring got $1^{\text {st }}$ rank having mean and standard deviation of $4.32 \pm 1.053$. Crop's residues burning after harvesting in developing countries are the source of emission of carbon dioxide and pollution in the environment and main cause of the temperature increase (Jing and Singh, 2020; Zommers et al., 2020). Deforestation ranked at $2^{\text {nd }}$ with mean and S.D $4.32 \pm 1.05$ because once the reason of climate change prevailed the sugarcane growers. Deforestation is the major threats and one of the main reasons of climate change resulted the environmental changes in developing countries especially in Pakistan (Gomes et al., 2019; Ullah et al., 2020). Respondents also perceived that excess of $\mathrm{CO} 2$ from agriculture activities had an impact on climate change and was ranked at $3^{\text {rd }}$ with mean $3.74 \pm 1.09$. Greenhouse gasses emission from industries and agriculture activities are the main cause of the climate change result in the increased frequency and intensity of extreme weather events in developing countries (Zhao and $\mathrm{Li}, 2015)$. The table also initiated that farm operation got $4^{\text {th }}$ rank with mean and standard deviation of 3.42 \pm .748. The results are in line with Powlson et al. (2014), who indicated that conventional practices during farm operations are also source of carbon emission resulted climate change. So, in this regard, conservation practices are important for friendly environment and to improve the soil heath conditions (Busari et al., 2015). 
Results clearly indicated that natural changes got 5 th rank having mean and S. D 3.03 \pm .991 . Different activities by the residents themselves are the main reason of climate change (Busari et al., 2015). Results clearly indicated that natural changes got 5 th rank having mean and S. D 3.03 \pm .991. Different activities by the residents themselves are the main reason of climate change (Busari et al., 2015). Table 1 presented that that rank 6th having mean and S.D 3.12 \pm .611 . These results are line with Raza et al. (2019) who indicated that pesticides have a negative impact not only on the environment but also on human health. Illiterate and lack of awareness had challenge of proper use of pesticides. Sugarcane farmers in tehsil Sadiqabad are facing different health and environmental problems. Furthermore, majority of the farmers are using over dose of pesticides, which is directly affecting the human health and increase the resistant among sugarcane pests. The table also initiated that synthetic fertilizer got 7th rank with mean and standard deviation of $2.96 \pm .999$. It was concluded that widely apply synthetic fertilizers are the also significant contributor to climate change. Use of synthetic fertilizer inefficient way is one of the reasons of environmental issue (Kanter, 2018).

Table 1. Perceived comprehensions of climate change by the respondents.

\begin{tabular}{lcc}
\hline Statement & Mean \pm Std. Deviation & R.0 \\
\hline Residue burring & $4.73 \pm .616$ & 1 \\
Deforestation & $4.32 \pm 1.053$ & 2 \\
Excess of CO2 from agriculture activity & $3.74 \pm 1.097$ & 3 \\
Farm operation & $3.42 \pm .748$ & 4 \\
Natural changes & $3.03 \pm .991$ & 5 \\
Excess use of pesticides & $3.12 \pm .611$ & 6 \\
Synthetic fertilizer & $2.96 \pm .999$ & 7 \\
\hline
\end{tabular}

Different attitude of the respondents regarding climate change are presented in figure 4 . more than thirty-five (35.5\%) of the respondents had said that climate change while $31.7 \%$ of the growers were confused and $15.6 \%$ of the growers had helpless about climatic variation. Almost $13.9 \%$ of the respondents had not belief on climate change.



Figure 4. Perceive attitude of sugarcane growers regarding climate change.

The perception of the sugarcane grower regarding climate change is presented in figure 5. It indicates that majority $(98.3 \%)$ of the growers had said increased duration of summer and $75 \%$ of the respondents had said deforestation has increased in the study area. About 65.5 $\%$ of the respondents answered that temperature increased since last ten years. About $60.1 \%$ of the sugarcane growers perceive changed in deforestation.
Almost $54 \%$ of the sugarcane growers perceive that increased flood have been observed in the study area. These observations are supported by the findings of Ali et al. (2017) who indicated that changed in temperature and rainfall as the evidence of climate change (Farooq and Gheewala, 2020) who indicated that climate change is the major threat for sugarcane yield. 


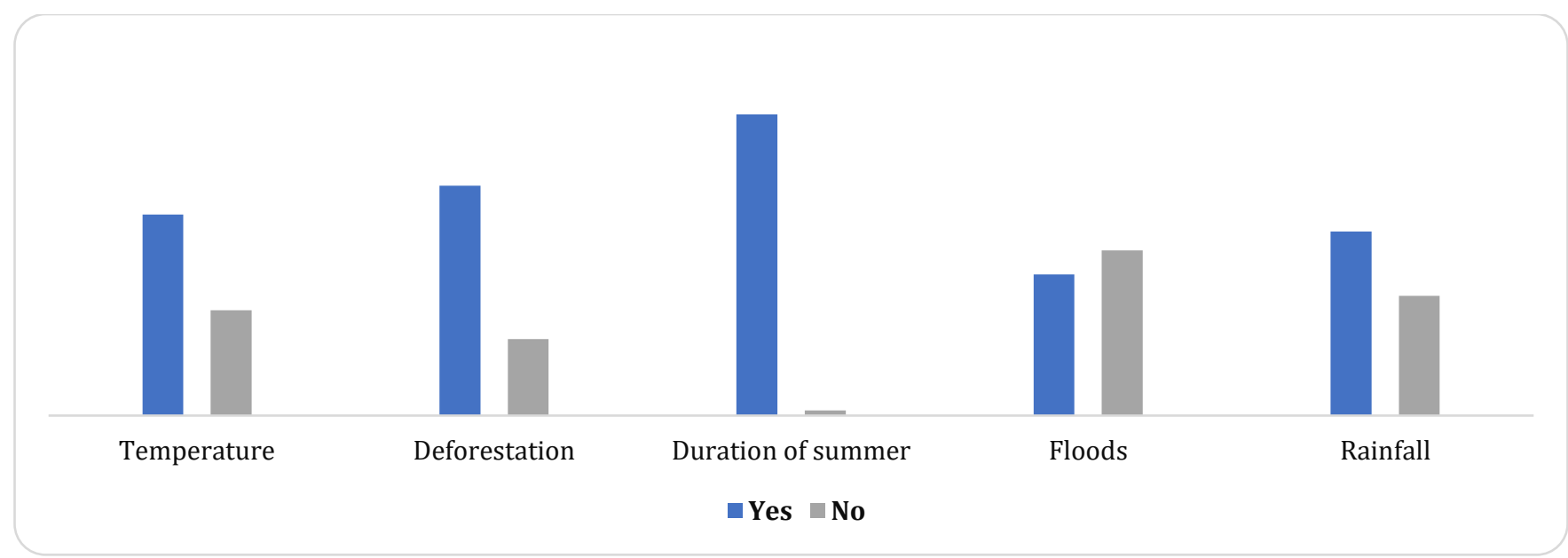

Figure 5. perceived the perception of sugarcane growers about climate change.

\section{CONCLUSION}

Different reasons of climate change were identified in the study area. Among various reasons of climate change, residue burring, deforestation, excess of $\mathrm{CO}_{2}$ from agriculture activities and farm operation were dominant. The majority of the growers conformed that increase duration of summer and deforestation has increased from last few years. It was concluded that increased air temperature, rainfall, long summers, and short winter have a direct impact on sugarcane production. It also increases evaporation, weeds, exhaustion, and temporary withering of plants. The adaptation of sugarcane management practices towards climate change were inadequate in the study area. Therefore, sugarcane productivity is affected by climate change adversely. As a result, farmers are facing problems in the form of low average sugarcane production under such circumstances. Therefore, there is an urgent need to raise awareness regarding the proper adoption of cultural practices to cope with the effects of climate change on agriculture and especially on sugarcane production.

\section{REFERENCES}

Abid, M., J. Scheffran, U.A. Schneider and E. Elahi. 2019. Farmer perceptions of climate change, observed trends and adaptation of agriculture in pakistan. Environmental Management, 63(1): 110-123.

Ali, S., Y. Liu, M. Ishaq, T. Shah, A. Ilyas and I. U. Din. 2017. Climate change and its impact on the yield of major food crops: Evidence from Pakistan. Foods, 6(6), 39.

Azadi, Y., M. Yazdanpanah and H. Mahmoudi. 2019. Understanding smallholder farmers' adaptation behaviors through climate change beliefs, risk perception, trust, and psychological distance: Evidence from wheat growers in iran. Journal of Environmental Management, 250: 109456.

Busari, M.A., S.S. Kukal, A. Kaur, R. Bhatt and A.A. Dulazi. 2015. Conservation tillage impacts on soil, crop and the environment. International Soil and Water Conservation Research, 3: 119-129.

Chatta, M.U., I. Khan and M.U. Hussain. 2018. Sugarcane production. Faisalabad, Pakistan: Office of the university books and magazines ( $1^{\text {stEd}}$ ), University of Agriculture Faisalabad, Pakistan. University Press.

Chohan, M. 2019. Impact of climate change on sugarcane crop and remedial measures-a review. Pakistan Sugar Journal, 34(1): 15-22.

Cuni-Sanchez, A., P. Omeny, M. Pfeifer, L. Olaka, M.B. Mamo, R. Marchant and N.D. Burgess. 2019. Climate change and pastoralists: Perceptions and adaptation in montane kenya. Climate and Development, 11(6): 513-524.

Deressa, T., R. Hassan and D. Poonyth. 2005. Measuring the impact of climate change on South African agriculture: The case of sugarcane growing regions. Agrekon, 44: 524-542.

Farooq, N. and S.H. Gheewala. 2020. Assessing the impact of climate change on sugarcane and adaptation actions in Pakistan. Acta Geophysica, 68: 14891503.

Gomes, V.H., I.C. Vieira, R.P. Salomão and H. Ter Steege. 2019. Amazonian tree species threatened by deforestation and climate change. Nature Climate Change, 9: 547-553. 
Hussain, S., A. Khaliq, U. Mehmood, T. Qadir, M. Saqib, M.A. Iqbal and S. Hussain. 2018. Sugarcane production under changing climate: Effects of environmental vulnerabilities on sugarcane diseases, insects and weeds. In: Climate change and agriculture. IntechOpen.

Jing, F. and R.P. Singh. 2020. Optical properties of dust and crop burning emissions over India using ground and satellite data. Science of The Total Environment, 718: 134476.

Kanter, D.R. 2018. Nitrogen pollution: a key building block for addressing climate change. Climatic Change, 147: 11-21.

Käyhkö, J. 2019. Climate risk perceptions and adaptation decision-making at Nordic farm scale-a typology of risk responses. International Journal of Agricultural Sustainability, 17: 431-444.

Khan, I., H. Lei, I.A. Shah, I. Ali, I. Khan, I. Muhammad, X. Huo and T. Javed. 2020. Farm households' risk perception, attitude and adaptation strategies in dealing with climate change: Promise and perils from rural Pakistan. Land Use Policy, 91: 104395.

Nadeem, M., A. Tanveer, H. Sandhu, S. Javed, M.E. Safdar, M. Ibrahim, M.A. Shabir, M. Sarwar and U. Arshad. 2020. Agronomic and Economic Evaluation of Autumn Planted Sugarcane under Different Planting Patterns with Lentil Intercropping. Agronomy, 10: 644.

Powlson, D.S., C.M. Stirling, M.L. Jat, B.G. Gerard, C.A. Palm, P.A. Sanchez and K.G. Cassman. 2014. Limited potential of no-till agriculture for climate change mitigation. Nature Climate Change, 4:678-683.

Prasara-A, J. and S.H. Gheewala. 2016. Sustainability of sugarcane cultivation: case study of selected sites in north-eastern Thailand. Journal of Cleaner Production, 134: 613-622.

Qureshi, M.A. and S. Afghan. 2005. Sugarcane cultivation in Pakistan. Sugar Book Pub. Pakistan Society of Sugar Technologist.

Raza, H.A., R. Amir, M.A. Idrees, M. Yasin, G. Yar, N. Farah and M. Younus. 2019. Residual Impact Of Pesticides On Environment And Health Of Sugarcane Farmers In Punjab With Special Reference To Integrated Pest Management. Journal Global Innovation Agriculture Social Science, 7: 79-84.

Shakoor, U., M. Rashid, M. Iftikh-Ul-Husnain and T. Arif. 2019. Vulnerability of sugarcane crop production to climate change in pakistan: an empirical investigation. Proceedings Book.101.

Trenberth, K.E. 2011. Changes in precipitation with climate change. Climate Research. 47: 123-138.

Trenberth, K.E. 2012. Framing the way to relate climate extremes to climate change. Climatic Change, 115: 283-290.

Ullah, S., T. Gang, T. Rauf, F. Sikandar, J.Q. Liu and R.S. Noor. 2020. Identifying the socio-economic factors of deforestation and degradation: a case study in Gilgit Baltistan, Pakistan. GeoJournal, 86: 1-14.

Zhao, D. and Y.-R. Li. 2015. Climate change and sugarcane production: Potential impact and mitigation strategies. International Journal of Agrononmy, 2015: 01-10.

Zommers, Z., P. Marbaix, A. Fischlin, Z.Z. Ibrahim, S. Grant, A.K. Magnan, H.-O. Pörtner, M. Howden, K. Calvin and K. Warner. 2020. Burning embers: towards more transparent and robust climate-change risk assessments. Nature Reviews Earth \& Environment, 1: 516-529.

\section{CONFLICT OF INTEREST}

The authors declare that they have no conflicts of interest.

\section{AUTHORS CONTRIBUTIONS}

All the authors contributed equally to this work.

Publisher's note: EScience Press remains neutral with regard to jurisdictional claims in published maps and institutional affiliations.

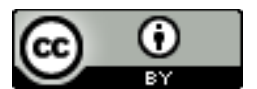

Open Access This article is licensed under a Creative Commons Attribution 4.0 International License, which permits use, sharing, adaptation, distribution and reproduction in any medium or format, as long as you give appropriate credit to the original author(s) and the source, provide a link to the Creative Commons license and indicate if changes were made. The images or other third-party material in this article are included in the article's Creative Commons license, unless indicated otherwise in a credit line to the material. If material is not included in the article's Creative Commons license and your intended use is not permitted by statutory regulation or exceeds the permitted use, you will need to obtain permission directly from the copyright holder. To view a copy of this license, visit http://creativecommons.org/licenses/by/4.0/. 